\title{
DIDÁTICA MULTIDIMENSIONAL: POR UMA SISTEMATIZAÇÃO CONCEITUAL*
}

\author{
Maria AmÉlia Santoro Franco ${ }^{1}$ \\ Selma Garrido Pimenta ${ }^{2}$
}

RESUMO: O texto discute possíveis articulações entre os princípios pedagógicos da Didática e das Didáticas Específicas, com o objetivo de configurar o estatuto de uma Didática Multidimensional. A pesquisa de natureza teórica parte do pressuposto de que os saberes ensinados são reconstruídos pelos sujeitos educadores e educandos, o que lhes possibilita se tornarem autônomos, emancipados, questionadores. A partir da questão central - a Didática e as Didáticas Específicas têm oferecido fundamentos a essa prática? - , analisa os limites da transposição didática nas didáticas específicas, e da perspectiva normativa na didática, que minimizam a complexidade do ensinar, o que pode ser superado configurando-se uma Didática Multidimensional.

Palavras-chave: Didática multidimensional. Transposição didática. Ensinar. Aprender.

\section{MULTIDIMENSIONAL DIDACTICS: FOR A CONCEPTUAL SYSTEMATIZATION}

\begin{abstract}
This article discusses possible connections between pedagogical principles of Didactics and Specific Didactics, in order to set the status of a Multidimensional Didactics. The research has a theoretical nature and assumes that teachers and students reconstruct the knowledge taught, which process enables them to become autonomous, emancipated, questioners. From the central issue Didactics and Specific Didactics have offered foundations for this practice? - it examines the limits of didactics transposition in Specific Didactics, and of normative perspective of Didactics, which minimize the complexity of teaching. This could be overcome by setting up a Multidimensional Didactics.
\end{abstract}

Keywords: Multidimensional didactics. Didactics transposition. Teach. Learn.

\footnotetext{
*Artigo resultado do projeto de pesquisa "Ensino e pesquisa nos cursos de graduação: ensinando com pesquisa e pesquisando o ensinar" financiado pelo CNPq.

${ }^{1}$ Universidade Católica de Santos - Santos (SP), Brasil. E-mail: ameliasantoro@uol.com.br

${ }^{2}$ Universidade de São Paulo - São Paulo (SP), Brasil. E-mail: sgpiment@usp.br

DOI: 10.1590/ES0101-73302016136048
} 


\title{
DIDACTIQUE MULTIDIMENSIONNELLE: POUR UNE SYSTÉMATISATION CONCEPTUELLE
}

\begin{abstract}
RESUME: Ce texte propose de discuter les éventuelles articulations entre les principes pédagogiques de la Didactique et des Didactiques spécifiques dans le but de mettre en place le statut d'une Didactique Multidimensionnelle. Il se base sur le présupposé théorique que les savoirs sont reconstruits aussi bien par les sujets éducateurs que par les sujets éducants, leur permettant de devenir autonomes, émancipés, critiques. À partir de la question centrale : "La Didactique et les Didactiques Spécifiques offrent-elles des fondements à cette pratique ? ", l'article analyse les limites de la transposition didactique des didactiques spécifiques ainsi que celles de la perspective normative de la didactique, qui réduisent la complexité de l'enseignement. Ce que la mise en place d'une Didactique Multidimensionnelle entend dépasser.
\end{abstract}

Mots-clés: Didactique multidimensionnelle. Transposition didactique. Enseigner. Apprendre.

\section{Introdução}

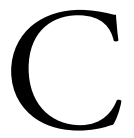

onsideramos que os saberes ensinados são reconstruídos pelos educadores e educandos e, a partir dessa reconstrução, os sujeitos têm possibilidade de se tornarem autônomos, emancipados, questionadores. Assim, como a Didática tem oferecido fundamentos a essa prática vislumbrada por Freire (1996)? A disciplina Didática, em suas origens, foi identificada, em diferentes países (CAMILLONI, 2013), a uma perspectiva normativa e prescritiva de métodos e técnicas de ensinar, que ainda permanece arraigada no imaginário dos professores brasileiros. Quando indagados sobre o que esperam da Didática, respondem: as técnicas de ensinar. $\mathrm{O}$ que evoluiu no campo do ensino de Didática para alterar essa expectativa?

Essas tensóes conceituais, decorrentes da dubiedade epistemológica da Didática, oscilando entre técnica prescritiva ou fundamentadora da reflexão docente, são analisadas neste texto.

O que a Didática pode oferecer, em seus fundamentos teóricos e metodológicos, aos professores em formação? Como articular uma Didática que tenha no sujeito aprendente o seu olhar e seu foco? Pudemos perceber em nossas investigaçóes que as didáticas específicas, muitas vezes, ao se preocuparem apenas com a transposição didática, minimizam a configuração complexa da prática do ensino. Assim, é proposta a discussão sobre as articulaçóes possíveis entre os princípios pedagógicos da epistemologia de uma Didática Fundamental com as Didáticas Específicas, recomendando o estatuto de uma Didática Multidimensional, que 
fundamente a prática do ensino como um fenômeno complexo e multirreferencial, uma vez que se observa que o foco excessivo na dimensão disciplinar retira da tarefa do ensino sua necessária multidimensionalidade.

Pode-se afirmar que a lógica da Didática é a lógica do ensino. No entanto, e contraditoriamente, essa vocação da Didática realiza-se apenas e tấo somente por meio da aprendizagem dos sujeitos envolvidos no processo. Portanto, a questáo da Didática amplia-se e complexifica-se ao tomar como objeto de estudo e pesquisa não apenas os atos de ensinar, mas o processo e as circunstâncias que produzem as aprendizagens e que, em sua totalidade, podem ser denominados de processos de ensino. Portanto, o foco da Didática, nos processos de ensino, passa a ser a mobilização dos sujeitos para elaborarem a construção/reconstruçáo de conhecimentos e saberes.

Assim, mais complexa que elaborar o ensino, numa perspectiva antiga de organizaçáo de transmissão de conteúdos, será agora a perspectiva de desencadear nos alunos atividade intelectual que lhes permita criar sentido às aprendizagens e, só assim, reelaborá-las e transformá-las em saberes.

Paulo Freire (2011) insiste nessa perspectiva desde os primórdios da Pedagogia do oprimido nos finais da década de 1970 e retoma suas ideias quando retorna ao Brasil no início do século XXI. Ele reafirma que "ensinar não é transferir conhecimento, mas criar as possibilidades para a sua produçáo ou a sua construçáo" (p. 24), realçando que essa perspectiva transforma o papel do professor e da Didática, uma vez que "quem forma se forma e reforma ao formar, e quem é formado forma-se e forma ao ser formado" (p. 25). Reitera, assim, que o educador deve ajudar os alunos a questionar sua realidade, problematizá-la e tornar visível o que antes estava oculto, desenvolvendo novos conhecimentos sobre ela.

Paulo Freire (2011) considera que quanto mais se exerce criticamente a capacidade de aprender, mais se constrói e se desenvolve o que denomina curiosidade epistemológica, conceito aproximado do que se denomina aqui como atividade intelectual do aluno, articulado aos conceitos de sentido e prazer em Charlot (2000). Aí está o papel contemporâneo da Didática que estamos denominando de Didática Multidimensional: uma Didática que tenha como foco a produção de atividade intelectual no aluno e pelo aluno, articulada a contextos nos quais os processos de ensinar e aprender ocorrem. Algo que se paute numa pedagogia do sujeito, do diálogo, cuja aprendizagem seja mediação entre educadores e educandos.

Os princípios epistemológicos da Didática Multidimensional emergem pesquisas realizadas nos últimos 20 anos, que evidenciam a insuficiência das Didáticas Específicas excessivamente voltadas à estruturação de conteúdos e métodos, o que acaba apequenando e impedindo a consideração do ensino em sua perspectiva multirreferencial e multidimensional. Os conceitos de curiosidade epistemológica (FREIRE, 2011), de multirreferencialidade (ARDOINO, 1992) e da relação com o 
saber (CHARLOT, 2000) estáo implicados na construção do conceito que propomos de Didática Multidimensional.

\section{Multidimensional ou Multirreferencial?}

O conceito de multirreferencialidade, cunhado por Ardoino (1992), foi de fundamental importância ao aprofundarmos pesquisas e estudos sobre a Pedagogia como ciência da educação, afirmando-a como a matriz articuladora dos diferentes aportes disciplinares que se debruçam sobre a educação. Assim, conforme Franco (2001),

Ora, as demais ciências, ao estudarem a realidade educacional utilizam-se de seus aportes epistemológicos que fundamentam seus métodos e recortam, para conferir sentido, seu objeto. Essa postura tem sistematicamente produzido uma visão distorcida da potencialidade desse objeto de estudo (a educaçáo) e talvez seja um dos fatores que poderão explicar o contínuo fosso entre teoria e prática educacional. (p. 35)

E ainda, de acordo com Pimenta (1996),

A fecundidade destas ciências, no entanto, é de pouco valor para a investigação pedagógica, pois o psicólogo, quando trabalha no campo educacional, não faz pedagogia. Ele tão somente aplica conceitos e métodos de sua ciência a um dos campos da atividade humana, no caso, a educação [...]. (p. 45)

Assim, a multirreferencialidade foi se constituindo em um apoio à nossa perspectiva de considerar a educação como campo de estudo de diferentes ciências, mas com aportes metodológicos diferentes. Entendemos que só a Pedagogia pode compreender o fenômeno educativo a partir da ótica do pedagógico. E Ardoino (1992) nos reforça quando afirma que a

[...] análise multirreferencial das situaçôes das práticas, dos fenômenos e dos fatos educativos se propóe explicitamente uma leitura plural de tais objetos, sob diferentes ângulos e em função de sistemas de referências distintos, os quais não podem reduzir-se uns aos outros. Muito mais que uma posição metodológica, trata-se de uma decisão epistemológica. (p. 7)

Ao estudarmos a Pedagogia, também consideramos importante a não redução de um aporte teórico sobre os outros. É a diversidade de aportes que nos interessa e que permite uma leitura plural e complexa dos fenômenos da educação. 
Entendendo a Pedagogia como ciência da prática e para a prática, realizamos estudos para reconfigurar seu método, que não pode se contentar com os aportes positivistas. Assim, conforme Franco (2001),

Mesmo a abordagem inter e multidisciplinar, integrando os conhecimentos produzidos pelas diversas ciências que estudam a educação, dificilmente poderá dar conta de compreender a essência do fenômeno educativo, pois os fenômenos ao serem apreendidos, pelas diferentes ciências, com diferentes intencionalidades, nem sempre terão pontos articuladores de convergência epistemológica [...] (p. 10)

Nessa perspectiva, é importante então analisar a proposta de Ardoino (1992) ao discutir a questão das ciências da educação. Este realça que,

apesar das tentativas para calcá-las mais ou menos sobre o padrão das ciências exatas, já não podemos nos contentar atualmente com uma aproximação somente "positivista" no marco das ciências antropossociais, no seio das quais se situam, incontestavelmente, diferentes olhares que pretendem dar conta cientificamente dos fenômenos que interessam à educação e às práticas que põem esta em ação. (p. 8).

Como espaço privilegiado da Pedagogia, estudamos e pesquisamos a Didática Geral, diferenciando-a das didáticas específicas, que são, para nós, metodologias voltadas à estruturação da parte do ensino que organiza os conteúdos das diferentes disciplinas. Temos concluído que, muitas vezes, o foco excessivo na dimensão disciplinar retira da tarefa do ensino sua necessária multidimensionalidade. Acreditamos que o ensino é uma atividade multidimensional em todas as esferas disciplinares. Empregamos esse termo, em complemento à abordagem multirreferencial, para reafirmar nossa convicção de que o ensino, de qualquer disciplina do saber, requer uma dinâmica de convergência nos atos e nas formas de ensinar. Requer fundamentos pedagógicos essenciais, pois é fenômeno complexo realizado entre os sujeitos professores e alunos, situados em contextos, imbricado nas condições históricas e mediado por múltiplas determinaçōes.

Considerando que o ensino na sociedade se desenvolve intencionalmente nas instituições escolares, faz-se necessário explicitar os princípios de uma Didática Geral que articule e fundamente os processos de mediação entre a teoria pedagógica e a ação de ensinar.

A concretização do ensino em sala de aula extrapola e transcende a perspectiva das didáticas específicas cujo foco é a estrutura metodológica e conceitual dos conteúdos. A tessitura dos conteúdos e sua necessária transposição didática requerem a contínua articulação entre os princípios educativos, a intencionalida- 
de pedagógica e a especificidade das condiçóes dadas. Essa triangulação solicita base sólida de princípios e valores, de forma a não se tornar uma mera aplicação de modos de fazer. A didática específica, por sua vez, requer uma base de fundamentos para bem se articular com o todo, base essa já assinalada na perspectiva de Chevallard (1991) em La transposición didáctica: del saber sabio al saber enseñado. No entanto, o que é o saber sábio senão um antecedente que fundamenta e dirige o ensinado? Cremos que há, ou pode haver, um processo contínuo de simplificação dos conteúdos disciplinares para se adaptarem às limitaçóes do saber ensinado. Aliás, a própria percepção de que algo pode ser ensinado de fora para dentro pode apequenar a dimensão do saber sábio. Além de minimizar e mesmo subtrair os sujeitos aprendentes e ensinantes, ao afirmar que toda disciplina (da matemática, no caso de Chevallard, e de todo o IREM ${ }^{1}$, na França) possui uma lógica imanente da qual decorre a lógica de ensiná-la, nesse caso, considera-se que são somente os especialistas das disciplinas aqueles que têm competência para saber e dizer como ensiná-la. Nessa ótica, os professores, em que pese sua colaboração nesse processo, seriam quase os técnicos que executariam o que foi definido pelos especialistas. Vários autores têm estudado os perigos dessa simplificação. Por exemplo, Luccas (2004) afirma que

A ausência da segunda transposiçáo didática e a presença da simplificaçáo sofrida pelo saber, a nosso ver, apresenta-se como um dos fatores responsáveis pelo fracasso no atual ensino, como muitas pesquisas vêm apontando. Acreditamos que a existência da simplificação deve-se, principalmente, à falta de formação apropriada dos responsáveis para trabalharem com a transposição didática. (p. 123; grifos do autor)

Davini (2013) se refere ao problema das didáticas das disciplinas (em especial à Transposição Didática) de estarem

[...] elaborando uma "teoria diafragmática" [que] ao colocar seu foco em uma ou duas dimensóes, reduzem o processo de ensino a uma tarefa formativa nas disciplinas separadas entre si constituindo teorias autonomizadas e fragmentárias. (p. 54)

Há que se pensar na imponderabilidade dessa transposição: quem a faz? Como a faz? O professor é o responsável por essa transposição? Como não desprezar o saber sábio que antecede o saber científico? Para Chevallard (1991), a Transposição Didática é feita por uma instituição 'invisível', uma 'esfera pensante' que ele nomeou de Noosfera: professores, instituiçóes, livros didáticos, universidades, redes de ensino, etc.. Cabe indagar: como articular interesses/valores/ perspectivas de tantas ordens? Como permitir que essas didáticas de cada disciplina caminhem de maneira tão avulsa e não coordenadas? Será que Luccas (2004) tem razão quando afirma que a transposição é um dos fatores que explicariam o 
fracasso das salas de aula? E que um dos fatores que contribuem para isso é o tratamento fragmentado do saber escolar, fragmentado (e mesmo enclausurado) em cada disciplina, conforme Davini (2013)?

Chevallard (1991) aponta a necessidade de um trabalho interno no processo de transposição, em que o professor é o responsável por esse novo momento na transformação do conteúdo. No entanto, nós nos perguntamos: quem é esse professor? Onde está o coletivo de professores? De que forma foi realizada a formaçáo desse professor? Pode ele produzir adequadamente o que dele se espera? Há fragilidades que precisam ser superadas, especialmente na articulação dessas duas esferas da transposição. Há a necessidade de um rigor e uma vigilância epistemológica, do contrário, os saberes se perderão num labirinto de pequenas interpretaçôes.

Compreendemos que há um trabalho político-pedagógico necessário para que os conteúdos escolares sejam negociados, filtrados, escolhidos, propostos. Essa ideia existe desde Comenius. Concordamos com Gimeno-Sacristán (1996, p. 42) quando realça que "uma das razóes de ser do saber-fazer pedagógico tem sido propiciar a elaboração da cultura transmissível para que seja assimilável por determinados receptores".

Essa possível simplificação que a transposição pode gerar foi também comentada por Lopes (1999, p. 208) quando propôs o conceito de mediação didática em substituição ao conceito de transposição didática, sugerindo uma perspectiva dialética que substituísse a ideia de reprodução ou mesmo de um "movimento de transportar de um lugar a outro, sem alteraçóes".

Também Forquin (1993) relembra a importância do resgate da dimensáo epistemológica na discussão do conhecimento escolar. $\mathrm{O}$ autor preconiza o retorno à lógica pedagógica em oposição à razão sociológica que, por muito tempo, impregnou os estudos de construçáo dos saberes curriculares.

Lopes (1999) vai mais adiante e reafirma o que talvez estejamos buscando com a Didática Multidimensional:

Além da crítica de Forquin, defendo que o papel da epistemologia não se resume à discussão da validade epistemológica dos saberes, mas na possibilidade de introduzir uma nova forma de compreender e questionar o conhecimento, internamente, na sua própria forma de se constituir. (p. 167, grifos nossos)

$\mathrm{Na}$ seleção de conteúdos didáticos, para além das questóes específicas postas pelas didáticas das disciplinas, há toda uma teoria pedagógica presente na formulação de projetos de organização da escola.

Os conteúdos a serem ensinados passam necessariamente pela análise das diferentes culturas presentes nas instituiçóes, bem como pela análise das tensóes e dos valores necessários à explicitação das finalidades do ensino; pela aná- 
lise das diversas e divergentes concepçóes de educação e ideologias presentes nos sistemas de ensino; e pela incorporaçâo de diferentes contribuiçôes das áreas de conhecimentos específicos no desenvolvimento humano que produzem processos de subjetividade e socialização dos sujeitos aprendentes e ensinantes.

Ao delinear conteúdos de ensino, há que se ocupar com as (novas) formas de comunicação entre as gerações; com o estudo e o desenvolvimento de modelos metodológicos e didáticos; com a formulação e crítica de critérios para a seleção de conteúdos e organização de atividades de aprendizagem, coerentes ao projeto educativo institucional; e com a ressignificação dos sistemas de avaliação para que sejam estratégias de inclusão, participação e indiquem caminhos de superaçáo dos problemas e das dificuldades dos estudantes e das escolas.

Ainda temos a considerar que todo processo didático está imbricado com as políticas de formação dos docentes em diferentes cenários, nacionais e internacionais, na busca de práticas que possibilitem o desenvolvimento de capacidades de reflexão crítica nos futuros docentes, ou seja, há múltiplas dimensões pedagógicas dos processos e das atividades formativas dos sujeitos que ensinam e que aprendem. Daí, entendemos que a essa Didática, que tem seu suporte na teoria pedagógica que parte da práxis educativa e a ela retorna, seria apropriado denominá-la de Multidimensional.

A Didática Multidimensional explicita assim seu campo próprio e dialoga com as didáticas específicas, porque há princípios formativos e pedagógicos que devem estar presentes em todo processo de ensino-aprendizagem, sem os quais esta não se realiza.

Afirmamos, assim, que a ausência desses fundamentos pedagógicos torna o ensino de qualquer disciplina em simples treinamento do fazer ou do pensar. Ou, conforme Franco (2010), ao considerar "[...] a Pedagogia [como] o espaço dialético para a compreensão e a operacionalização das articulaçôes entre a teoria e a prática educativa, e nessa direção ela se organiza como espaço comunicativo à Didática”, conclui que:

Não basta à Pedagogia refletir ou teorizar sobre o ato pedagógico; não basta à Pedagogia também, orientar ou, muito menos, prescrever açóes práticas para a concretização das práticas educativas. É preciso que a Pedagogia produza conhecimentos na direção da superação da fragmentação dos saberes pedagógicos, docentes e científicos que foram historicamente dissociados. (FRANCO, 2010, p. 32)

Quando falamos em multidimensionalidade, falamos de convergência, de fundamentos pedagógicos que subsidiam a proposta multirreferencial. Entendemos que há uma relação dialética entre multirreferencialidade e multidimensionalidade. A multirreferencialidade permite a compreensão das totalidades 
no todo, e a multidimensionalidade, do todo às totalidades. $\mathrm{O}$ multirreferencial nos ajuda a compreender a educaçáo em sua complexidade e totalidade, já a multidimensionalidade foca o ensino na perspectiva da totalidade. Portanto, conforme aponta Ardoino (1992),

[...] o problema que a análise multirreferencial se coloca é utilizar várias linguagens para a compreensão dos fenômenos sem misturá-las, sem reduzi-las umas às outras; o conhecimento produzido por essa postura seria, portanto, um conhecimento 'bricolado', 'tecido'. (p. 7-8)

A Didática Multidimensional afirma a perspectiva da totalidade, articulando as partes no todo como forma de síntese, superando a bricolagem por meio do filtro pedagógico ${ }^{2}$, o que nos permite ajustar e propor alguns de seus fundamentos.

\section{Por uma Didática Multidimensional}

O professor em sala de aula, oprimido por múltiplas condições difíceis de serem superadas, sempre nos pergunta: o que pode a Didática ajudar? Como a Didática, cujo objeto de estudo se concentra fortemente nos processos que ocorrem na sala de aula, com vistas às aprendizagens do aluno, pode ajudar o professor? Frente às dificuldades pedagógicas postas ao professor, o que pode "recomendar" a Didática?

Analisando as pesquisas que realizamos nos últimos 20 anos e com base em estudos de Freire (1997) e de Charlot (2000), passamos a reafirmar alguns fundamentos que consideramos essenciais à prática pedagógica docente:

1. As atividades que compõem o ensino resultam melhor quando envolvidas em processos investigativos. Alunos e professores, ao se articularem como pesquisadores em ação, passam a problematizar a realidade e a buscar alternativas de pensamento e reflexâo. Em vez de transmitir conceitos e conteúdos, a perspectiva será a de pesquisar a realidade envolvida com aquele conceito. É sabido que uma das melhores formas de envolver o aluno nas atividades é mobilizá-lo com perguntas, pesquisas, buscas e sínteses (FREIRE, 1979; CHARLOT, 2013; PIMENTA, 2012; FRANCO, 2013). A sala de aula transformada em oficina de busca e indagação produz aprendizagens mais consistentes que aquelas produzidas em ambientes de transmissão de conteúdos (GALLEÃO, 2014). A ação de ensinar como prática social é permeada por múltiplas articulaçôes entre professores, alunos, instituiçâo e comunidade, impregnadas pelos contextos socioculturais a que pertencem, formando um jogo de múltiplas confluências que se multideterminam num 
determinado tempo e espaço social, impregnando e configurando a realidade existencial do docente. Assim, o fazer docente estará sempre impregnado com as concepçóes de mundo, de vida e de existência dos sujeitos da prática. Dessa forma, só a pesquisa contínua e criteriosa pode colocar o professor em processo de contextualizaçáo do ensinar/ aprender (FRANCO, 2013) ou, como afirma Freire (2007, p. 86), "antes de qualquer tentativa de discussão de técnicas, de materiais, de métodos para uma aula dinâmica assim, é preciso — indispensável mesmo - que o professor se ache 'repousado' no saber de que a pedra fundamental é a curiosidade do ser humano. É ela que me faz perguntar, conhecer, atuar, perguntar mais, 're-conhecer'". É bom realçar que a Didática não recomenda técnicas, pois sabe que elas só são funcionais se denotarem uma forma de expressão significativa do professor para o processo de ensinar.

2. Paulo Freire, em toda sua obra, sempre se referiu à necessidade de se estabelecer entre alunos e professores um universo comum de conhecimento, a partir do qual poderiam ser estabelecidas as bases de um diálogo na perspectiva do logos, que vai então se estruturando e se construindo. Nesse processo, os sentidos vão sendo criados e transformados, conforme Charlot (2000). Assim, consideramos que esse segundo princípio seria a necessidade de processos dialogais na sala de aula. Historicamente, esse sentido de diálogo foi, muitas vezes, apropriado como senso comum. Há que se recordar que o diálogo precisa estar voltado à construção do conhecimento. Lembra-nos Freire (1979) que, para aprender, é preciso existir, e existir ultrapassa viver porque é mais do que estar no mundo. É estar nele e com ele, e é essa capacidade ou possibilidade de ligação comunicativa do existente com o mundo objetivo, contida na própria etimologia da palavra, que incorpora ao existir o sentido de criticidade que não há no simples viver. "Transcender, discernir, dialogar (comunicar e participar) são exclusividades do existir. O existir é individual, contudo só se realiza em relação com outros existires. Em comunicação com eles." (p. 57). Essa exigente proposta de diálogo como criticidade é fundamental para superar o sentido banal de diálogo como conversa. Em sala de aula, o diálogo adquire a perspectiva de problematização da realidade e de crítica. Essa é a dimensão que precisa ser buscada, a superação do empírico pelo concreto, o que se faz pelo diálogo e pela teoria. Esse processo cria sentido e mobiliza para a ação. Afirma Freire (1979) que uma educação dialogal e crítica poderá conduzir a uma transitividade crítica voltada para a responsabilidade social e política e essa transitividade se caracteriza "pela profundidade na interpretação dos problemas. Pela substituição de explicaçōes mágicas por princípios causais. [...] Pela prática do diálogo, e não da polêmica." (p. 85). 
3. Outro princípio que a Didática Multidimensional recomenda é a construçáo de processos de práxis na perspectiva freireana: "a práxis, como reflexão e ação dos homens sobre o mundo para transformá-lo. Sem ela, é impossível superar a contradição opressor-oprimido" (FREIRE, 1997, p. 38). Temos falado da importância da reflexão, no entanto, mais uma vez, há que se considerar que a apreensão apressada do conceito, por parte de muitos professores e pesquisadores, tem banalizado sua interpretação (PIMENTA, 2011) e impedido de ser uma proposta contra-hegemônica frente ao pragmatismo e ao tecnicismo que tem impregnado as práticas educativas e sociais. É preciso refletir a partir de um saber comum, de um saber contextualizado sobre o papel social e político da educação e do trabalho docente. Esse movimento da epistemologia reflexiva da prática, dentro da racionalidade crítica, tal qual proposta por Kemmis (1998), Barco (2013) e desenvolvida por Pimenta (2002), inova e organiza possibilidades de ruptura com algumas circunstâncias da cultura profissional institucionalizada que limitam o exercício e o desenvolvimento da autonomia intelectual dos docentes. Por isso, este é estratégico para a superação de condiçóes inadequadas do trabalho do professor. Vale a pena refletir com Imbert (2003) a distinçáo que faz entre prática e práxis, e atentando para a questão da autonomia e da perspectiva emancipatória, inerente ao sentido de práxis: "Distinguir práxis e prática permite uma demarcação das características do empreendimento pedagógico. Há, ou não, lugar na escola para uma práxis? Ou será que, na maioria das vezes, são simples práticas que nela se desenvolvem, ou seja, um fazer que ocupa o tempo e o espaço, visa a um efeito, produz um objeto (aprendizagem, saberes) e um sujeito-objeto (um escolar que recebe esse saber e sofre essas aprendizagens), mas que em nenhum momento é portador de autonomia" (p. 15). $\mathrm{O}$ exercício da práxis requer processos de conscientização do professor sobre o papel que desempenha na sala de aula, no mundo, na vida dos alunos. Somente um professor consciente dessas circunstâncias pode produzir mudanças e novas perspectivas na vida dos alunos.

4. A Didática Multidimensional realça a construção de processos de mediação. Como a Didática pode tornar possível o ensino? Como pode a Didática organizar um ensino que proceda à mediação reflexiva entre os valores e a cultura que a sociedade dissemina e os estudantes em formação? Pode a Didática sozinha dar conta dessa tarefa? É claro que não, no entanto, ela, como campo específico de conhecimento, tem uma responsabilidade social em acompanhar e refletir as mudanças que ocorrem no mundo e dar respostas para a ressignificaçáo dos processos de ensino na perspectiva da aprendizagem do aluno, contribuindo com os sujeitos desse processo e com a construçáo de situaçóes de aprendizagens significativas, dentre elas as aulas, para que sejam interessantes. 
Conforme Charlot (2000, p. 73), “[...] uma aula 'interessante’ é uma aula na qual se estabeleça, em uma forma específica, uma relação com o mundo, uma relação consigo mesmo e uma relação com o outro". A mediação didática aí penetra ao dispor aos docentes perspectivas de análise que os ajudem a compreender os contextos históricos, sociais, organizacionais, culturais, nos quais os sujeitos estão em relação com o saber a ser (re)aprendido. Assim, a Didática se estrutura nas possibilidades de mediação entre o ensino, prioritariamente, na responsabilidade de professores, e a aprendizagem dos alunos. Enfatizamos que Didática é, acima de tudo, a construção de conhecimentos que possibilitam a mediação entre o que é preciso ensinar e o que é necessário aprender; entre o saber estruturado nas disciplinas e o saber ensinável nas circunstâncias e nos momentos; e entre as atuais formas de relação com o saber e as novas formas possíveis de reconstruí-las.

5. Considerando a complexidade do ato pedagógico de ensinar e aprender em contextos, parece-nos relevante considerar que os saberes de várias áreas sejam mobilizados nesses contextos. À Didática Multidimensional, compete considerar os processos de redes de saberes, dispondo os saberes da ciência pedagógica na criação das atividades dos ensinantes e dos aprendentes, "não porque contenha diretrizes concretas válidas para 'hoje e amanhä, mas porque permite $(\mathrm{m})$ realizar uma autêntica análise crítica da cultura pedagógica, o que facilita ao professor [e à escola, acrescentamos] debruçar-se sobre as dificuldades concretas que encontra em seu trabalho, bem como superá-las de maneira criadora" (SUCHODOLSKI, 1979, p. 477). $\mathrm{Na}$ análise de pesquisas apresentadas em eventos nacionais e internacionais, percebe-se a existência de vasto leque temático - epistemologia didática; docência e pesquisa; relação professor-aluno-conhecimentos; autoridade e autoritarismo docente; avaliação; projeto pedagógico; metodologias específicas; relação comunicacional mediadas por tecnologias; formação de professores crítico-reflexivos e tantas outras que poderiam sugerir uma dispersão temática e perda de foco da didática.

No entanto, se considerarmos a complexidade do objeto da didática - o ensino como fenômeno complexo e prática social — , percebemos que as pesquisas estão apontando para uma abordagem que poderíamos denominar de multidimensional, para além da multirreferencialidade de um fenômeno, que não se esgota com a análise de uma única perspectiva, conforme Ardoino (1992),

Assumindo plenamente a complexidade da realidade sobre a qual se interroga, a multireferencialidade se propóe uma leitura plural dos objetos (práticos ou teóricos), sob diferentes ângulos, implicando diversos olhares e linguagens específicos. (p. 103) 
A Didática Multidimensional assume como pressuposto a noção de multirreferencialidade para subsidiar seu compromisso com o ensino (fenômeno complexo) no momento em que as pesquisas na área se voltam para as práticas, interrogando-as quanto aos seus resultados. Comporta, assim, uma intençáo claramente prática, mas também teórica, à medida que possibilita melhor compreender as práticas, numa perspectiva que se aproxima da curiosidade científica, mas também ética. Em outras palavras, a noção de multirreferencialidade na base da Didática Multidimensional aponta para o trabalho conjunto entre professores e pesquisadores no qual "o papel da teoria é o de alargar a compreensáo que se tem da prática, nos contextos nos quais se realiza (escola, sistemas de ensino, movimentos sociais), para criar as condiçóes objetivas de transformá-las no sentido que se faz necessário (da utopia que se deseja)" (PIMENTA, 1996, p. 70).

Em consequência, por meio da Didática Multidimensional, temos a intenção de valorizar o trabalho docente na perspectiva de dotar os professores de instrumentos de análise e de crítica, que os ajudem a compreender os contextos histórico, sociais, culturais, organizacionais nos quais ocorre sua complexa atividade docente.

\section{Notas}

1. IREM: Instituts de recherche sur l'enseignement des mathématiques (institutos de pesquisa sobre o ensino das matemáticas).

2. Quando nos referimos a "filtro pedagógico" queremos afirmar que a Didática, ausente dos fundamentos pedagógicos, torna-se apenas uma tecnologia de ensinar. Estamos reafirmando a necessidade da articulação dialética entre conhecimento; professor e aquele a quem se destina o ensino; superando a perspectiva meramente tecnicista de separar e dividir o conhecimento para torna-lo assimilável a um sujeito imaginado; a Pedagogia nos lembra de que há um sujeito que aprende; aprende de determinada forma; transforma-se com o aprendido e com as tentativas de aprender; criando uma dinâmica que supera e transforma o pré-estabelecido planejado. O filtro pedagógico insere na didática específica, a lógica e as circunstâncias do sujeito aprendente. Vide FRANCO (2015).

\section{Referências}

ARDOINO, J. L'approche multireferentielle (plurielle) des situationes educatives et formatives. In: 25 ans des Sciences de l'éducation. Bourdeaux 1967-1992. Paris. INRP Institut National de la Recherche Pédagogique. 1992, p. 103-130.

BARCO, S. La corriente crítica en Didáctica - una mirada elíptica a la corriente técnica. In: CAMILLONI, A.W.; DAVINI, M.C.; EDELSTEIN, G.; LITWIN, E.; SOUTO, M.; BARCO, S. (Orgs.). Corrientes didácticas contemporáneas. 9. ed. Buenos Aires: Paidós, 2013, p. 158-167. 
CAMILLONI, A.W. De herencias, deudas y legados. Una introducción a las corrientes actuales de la didáctica. In: CAMILLONI, A.W. (Orgs.). Corrientes didácticas contemporáneas. 9. ed. Buenos Aires: Paidós, 2013. p. 17-40.

CHARLOT, B. Da relação com o saber, elementos para uma teoria. Porto Alegre: ARTMED, 2000.

Da relação com o saber às práticas educativas. São Paulo: Cortez, 2013.

CHEVALLARD, Y. La transposition didactique: du savoir savant au savoir ensigné. Grenoble: La pensée Sauvage, 1991.

DAVINI, M.C. Conflictos en la evolución de la didáctica. La demarcación de la ditáctica general y las didácticas especiales. In: CAMILLONI, A.W.; DAVINI, M.C.; EDELSTEIN, G.; LITWIN, E.; SOUTO, M.; BARCO. (Orgs.). Corrientes didácticas contemporáneas. 9. ed. Buenos Aires: Paidós, 2013. p. 41-76.

FORQUIN, J.C. Escola e cultura: as bases sociais e epistemologia do conhecimento escolar. Porto Alegre: Artes Médicas, 1993.

FRANCO, M. A. R. S. A pedagogia como ciência da educação: entre epistemologia e prática. 257 f. Tese (Doutorado) - Faculdade de Educação, Universidade de São Paulo, São Paulo, 2001.

Práticas pedagógicas de ensinar-aprender: por entre resistências e resignaçóes.

Educação e Pesquisa, v. 41, n. 3, p. 601-614, 2015

. Observatório da prática docente. Relatório CNPQ. São Paulo, 2010.

. Didática: uma esperança para as dificuldades pedagógicas do ensino superior?

Revista Práxis Educacional. v. 9, n. 15, p. 147-166, 2013.

FREIRE, P. A educação como prática da liberdade. São Paulo; Paz e Terra, 1979.

. Pedagogia da Autonomia - Saberes Necessários à Prática Educativa. 43a Ed. São Paulo: Editora Paz e terra; 2011

. Pedagogia do oprimido. 24. ed. Rio de Janeiro: Paz e Terra, 1997.

. Educação e mudança. 30. ed. Rio de Janeiro: Paz e Terra, 2007.

Pedagogia da autonomia: saberes necessários à prática educativa. São Paulo: Paz e Terra, 1996.

GALLEÂO, A.M. A aula universitária: espaçotempo de formação humana. Dissertação (Mestrado) - Universidade Católica de Santos, Santos, 2014. 304 p.

GIMENO-SACRISTÁN, J. O currículo: uma reflexão sobre a prática. 3. ed. Porto Alegre: ARTMED, 1996.

IMBERT, F. Pour une praxis pédagogique. Nantes: Matrice, 2003.

KEMMIS, S. El curriculum: más allá de la teoria de la reproducción. Madrid: Morata. 1998.

LOPES, A.R.C. Pluralismo cultural em políticas de currículo nacional. In: MOREIRA, A.F.B. (Org.). Currículo: políticas e práticas. Campinas: Papirus, 1999. p.59-80. 
LUCCAS, S. Abordagem histórico-filosófica na educação matemática: apresentação de uma proposta pedagógica. 204 f. Dissertação (Mestrado) - Universidade Estadual de Londrina, Londrina, 2004.

PIMENTA, S.G. Pedagogia, ciência da educação? São Paulo: Cortez, 1996.

Por una re-significatión de la Didáctica - Ciencia de la Educación, Pedagogie y Didáctica (una revisión conceptual y una sintesis provisional). Temps d'Educació, v. 19, p. 221-251, 1998.

. (Org.). Pedagogia e pedagogos: caminhos e perspectivas. São Paulo: Cortez, 2002.

. Epistemologia da prática ressignificando a didática. In: FRANCO, M.A.R.S.; PIMENTA, S.G. (Orgs.). Didática: embates contemporâneos. São Paulo: Loyola, 2011. p. $15-42$.

O protagonismo da Didática nos cursos de Licenciatura: a Didática como campo disciplinar. In: MARIN, A. J.; PIMENTA, S. G. (Orgs.). DIDÁTICA - teoria e pesquisa. Araraquara: J\&M, 2012. p. 54-68.

SUCHODOLSKI, B. Tratado de pedagogia. Barcelona: Península, 1979.

Recebido em 07 de junho de 2014.

Aprovado em 21 de março de 2016. 